\title{
Links Between Sex-Related Expectations About Alcohol, Heavy Episodic Drinking and Sexual Risk Among Young Men in a Shantytown in Lima, Peru
}

\begin{abstract}
CONTEXT: Alcohol use is frequently identified as a contributor to risky sexual behaviors; however, research results are mixed. Given the conflicting evidence, researchers have focused on other factors, such as expectations about alcohol's effects that might help explain the relationship of alcohol use and risky sexual behaviors.
\end{abstract}

METHODS: Cross-sectional data from 312 sexually experienced males aged 18-30 in a shantytown in Lima, Peru, were used in logistic regression models to identify associations of heavy episodic drinking and sex-related expectations about alcohol with sexual risk behaviors.

RESULTS: Heavy episodic drinking was associated with having had two or more sexual partners and having had sex with a casual partner in the past year (odds ratios, 2.8 and 2.5, respectively). After controlling for alcohol consumption, sex-related expectations about alcohol were associated with these high-risk sexual behaviors, as well as with not using a condom at last sex (1.2) and not using a condom at last sex with a casual partner (1.3).

CONCLUSION: Beliefs about the effect of alcohol on sexual performance could help explain links between alcohol consumption and risky sexual behavior not completely accounted for by the pharmacological effects of alcohol.

International Family Planning Perspectives, 2008, 34(1):15-20

Alcohol use is frequently identified as a contributor to risky sexual behaviors, such as young age at first sex, multiple partners, sex with casual partners or sex workers, and inconsistent condom use. ${ }^{1-4}$ However, the link between alcohol consumption and sexual behaviors may be mediated by expectations about alcohol's effects on these behaviors. ${ }^{5-8}$

Expectancy theory states that the more positive one's expectations are of the consequences of drinking, the more likely one will be to drink. ${ }^{9,10}$ Some studies have found that drinkers who believe alcohol consumption has positive effects on sexual performance tend to perceive fewer risks associated with unprotected sex and engage in a greater number of risky sexual behaviors than do those who do not have such beliefs: ${ }^{11-14}$ other studies, however, have not. ${ }^{15}$ Most of the research on this topic has been conducted in developed countries, some was done in specific populations such as college drinkers ${ }^{11,14}$ and some did not adequately control for alcohol consumption levels. ${ }^{13}$

In Peru, approximately 90\% of individuals aged 12-64 who live in urban areas have drunk alcohol; the average age at first alcohol consumption is $17 .{ }^{16} \mathrm{Alcohol}$, however, is not generally consumed daily during meals as it is in other countries; instead, drinking occurs mostly on weekends, at social gatherings and parties. Overall, 19-29-yearolds are the age-group most likely to consume alcohol every week (35\%).

This article examines the links between heavy episodic drinking, sex-related expectations about alcohol and sexual risk behaviors among 18-30-year-old males in Peru, and addresses gaps in the existing literature. First, we look at an important research question that has not been completely addressed: whether sex-related alcohol expectations are independently associated with risky sexual behaviors in a community sample, after controlling for heavy episodic drinking. Second, no previous studies have investigated the effect of sex-related expectations about alcohol on the link between alcohol consumption and sexual behaviors in Latin America. Nearly all this work has been done in the United States and Europe; however, the spread of HIV is currently most rapid in the developing world. Better understanding of factors associated with sexual risk behaviors in different cultural contexts is important if the global threat of STIs and HIV is to be reduced. ${ }^{17-20}$

\section{METHODS}

Study Site

This study was conducted in Las Pampas de San Juan de Miraflores, a shantytown located about 15 kilometers south of downtown Lima. The town has a population of 40,000 inhabitants, approximately $25 \%$ of whom are stably employed; in 2000, the estimated annual median income was $\$ 2,100 . .^{21}$ Las Pampas de San Juan de Miraflores was settled more than 20 years ago, so although many of the settlers came from different regions of the country, most of the young people living there today were raised there and are fluent in Spanish. Since 1986, the community of Las Pampas de San Juan de Miraflores has been under health surveillance by physicians, public health care workers, nurses and social workers from the Peruvian nongovernmental organization, A.B. Prisma. ${ }^{21-23}$
By Juan Antonio Gálvez-Buccollini, Valerie Paz-Soldan, Phabiola Herrera, Suzanne DeLea, Robert H. Gilman and James $C$. Anthony

Juan Antonio GálvezBuccollini and Phabiola Herrera are medical researchers, and Robert H. Gilman is medical research director, all with Asociación Benéfica PRISMA, Lima, Peru; Valerie Paz-Soldan is research assistant professor, Tulane University School of Public Health and Tropical Medicine, New Orleans, LA, USA; Suzanne DeLea is a medical student, School of Medicine, University of New Mexico, Albuquerque, New Mexico, USA; and James C. Anthony is chairman, Department of Epidemiology, School of Medicine, Michigan State University, Lansing, MI, USA. 


\section{Study Design}

All residents of Las Pampas de San Juan de Miraflores had been registered during a census completed for previous epidemiological studies. For this study, we used a simple random selection scheme to select 508 men and 460 women aged 18-30 from the census registry to participate in our study. Trained research assistants familiar with the community went to the homes of the selected individuals up to three times to invite them to participate; each health promoter was fluent in Spanish and underwent a monthlong training course that included role-playing and mock interviews. Health promoters explained the objectives, risks and benefits of the study to potential participants, and stressed that involvement was voluntary and could be discontinued at any time. Those who wished to participate gave written consent and were enrolled in the study.

Of the 508 men contacted, 11 refused to participate and 97 were unavailable for interviews; among the 460 women contacted, 5 refused to participate and 55 were unavailable for interviews. Data collection took place in two parts: an interview administered by the health promoters, which lasted approximately 25 minutes, and a self-administered questionnaire, which took approximately 15 minutes to complete. Respondents answered questions about social and demographic characteristics (e.g., age, education and marital status), alcohol use, sexual behavior and sexrelated alcohol expectations; to minimize the reluctance of respondents to answer questions on sexual behavior and sex-related alcohol expectations, items asking about these topics were contained in the self-administered questionnaire. This study was reviewed and approved by the A.B. Prisma Institutional Review Board for protection of human subjects in research.

For our analyses, we excluded women. Very few women reported any type of drinking, including heavy episodic drinking. This is consistent with previous studies in Peru that report a low prevalence of alcohol use disorders among women. ${ }^{16,24}$ Moreover, very few women reported risky sexual behaviors: For example, only four female respondents had had a casual partner in the previous year, and 16 had had multiple partners in the previous year. Because the female sample was small to begin with, and rates of drinking and risky sexual behaviors for women were low, an analysis of females would not have had sufficient power to identify associations between heavy episodic drinking or sex-related alcohol expectations and risky sexual behaviors.

Of the 400 men interviewed, seven were excluded from our analyses as a result of missing or invalid responses to key study variables. Our overall sample thus included 393 males aged 18-30. Because this sample was representative of the community, data were not weighted and design effects were irrelevant. Additional information from subjects who did not consent to participate or were unavailable to be interviewed was not collected. For our analyses, we restricted our sample to the 312 respondents who reported being sexually experienced.

\section{Measures}

- Dependent variables. The initial question on sexual intercourse, "Have you ever had sexual intercourse?", was followed by questions about our five outcomes of interest, each measured relative to the past year: having had two or more sexual partners, having had sex with a casual partner, having had sex with a sex worker, having had unprotected sex (not having used a condom at last sex) and having had unprotected sex with a casual partner. We inquired only about condom use at last sex, because previous studies suggest that it is a highly reliable indicator of risky sexual behavior. ${ }^{25}$

- Independent variables. We used a dichotomous measure of heavy episodic drinking, defined as having consumed at least five alcoholic drinks in a row at least once per month for the last 12 months, according to Slutske's definition. ${ }^{26}$ In addition, we included seven items measuring sex-related expectations about alcohol drawn from the Alcohol Expectancy Questionnaire: "I often feel sexier after I have had a couple of drinks," "I am a better lover after a few drinks," "Women can have orgasms more easily if they have been drinking," "I enjoy having sex more if I have had some alcohol," "I am more romantic when I drink," "I feel more masculine after a few drinks" and "After a few drinks, I am more sexually responsive." 27 Using the seven questions, we created a single continuous variable of sex-related alcohol

\begin{tabular}{|c|c|}
\hline Characteristic & $\begin{array}{l}\% \text { or mean } \\
(\mathrm{N}=312)\end{array}$ \\
\hline Mean age (SD) & $22.7(3.2)$ \\
\hline \multicolumn{2}{|l|}{ Marital status } \\
\hline Never-married & 79.5 \\
\hline Married & 3.2 \\
\hline Cohabiting & 17.0 \\
\hline Divorced & 0.3 \\
\hline \multicolumn{2}{|l|}{ Education } \\
\hline sprimary & 2.9 \\
\hline Secondary & 67.6 \\
\hline Technical & 21.1 \\
\hline University & 8.3 \\
\hline \multicolumn{2}{|l|}{ Sexual risk behavior in last year } \\
\hline$\geq 2$ sexual partners & 38.1 \\
\hline Sex with casual partner & 23.4 \\
\hline Sex with sex worker & 6.7 \\
\hline Unprotected last sex & 51.3 \\
\hline Unprotected last sex with casual partnert & 31.5 \\
\hline Heavy episodic drinker & 36.2 \\
\hline \multicolumn{2}{|l|}{ Sex-related alcohol expectations } \\
\hline I often feel sexier after a few drinks & 28.9 \\
\hline I am a better lover after a few drinks & 12.8 \\
\hline \multicolumn{2}{|l|}{ Women can have orgasms more } \\
\hline easily if they have been drinking & 48.1 \\
\hline I enjoy having sex more if I have had some alcohol & 55.8 \\
\hline I am more romantic when I drink & 1.6 \\
\hline I feel more masculine after a few drinks & 35.6 \\
\hline After a few drinks, I am more sexually responsive & 29.2 \\
\hline
\end{tabular}




\begin{tabular}{|c|c|c|c|c|c|c|c|c|c|c|}
\hline \multirow[t]{2}{*}{ Characteristic } & \multicolumn{2}{|c|}{$\geq 2$ partners } & \multicolumn{2}{|c|}{$\geq 1$ casual partners } & \multicolumn{2}{|c|}{$\begin{array}{l}\text { Sex with } \\
\text { sex worker }\end{array}$} & \multicolumn{2}{|c|}{$\begin{array}{l}\text { Unprotected } \\
\text { last sex }\end{array}$} & \multicolumn{2}{|c|}{$\begin{array}{l}\text { Unprotected last sex } \\
\text { with casual partnerf }\end{array}$} \\
\hline & Model 1 & Model 2 & Model 1 & Model 2 & Model 1 & Model 2 & Model 1 & Model 2 & Model 1 & Model 2 \\
\hline $\begin{array}{l}\text { Heavy episodic } \\
\text { drinking }\end{array}$ & $3.13^{* *}$ & $2.81^{* *}$ & $2.73^{* *}$ & $2.47^{* *}$ & $2.45 \dagger$ & 2.06 & 1.01 & 0.87 & 1.98 & 1.54 \\
\hline $\begin{array}{l}\text { Sex-related alcohol } \\
\text { expectations }\end{array}$ & na & $1.19^{*}$ & na & $1.16+$ & na & $1.26+$ & na & $1.24^{* *}$ & na & $1.33^{*}$ \\
\hline Age & 0.93 & 0.93 & $0.91^{*}$ & $0.90^{*}$ & 1.10 & 1.10 & $0.92^{*}$ & $0.92^{*}$ & 0.96 & 0.96 \\
\hline Marital status & $5.53^{* *}$ & $5.39 * *$ & $4.34^{* *}$ & $4.21^{* *}$ & 1.93 & 1.76 & $0.14^{* *}$ & $0.13^{* *}$ & 1.06 & 0.94 \\
\hline Education & 1.25 & 1.36 & 1.19 & 1.29 & 0.75 & 0.89 & 0.94 & 1.05 & 0.89 & 1.05 \\
\hline Prob $>c h i^{2}$ & 0.000 & 0.000 & 0.000 & 0.000 & 0.184 & 0.086 & 0.000 & 0.000 & 0.546 & 0.110 \\
\hline Pseudo $R^{2}$ & 0.1227 & 0.1343 & 0.0962 & 0.1049 & 0.0404 & 0.0626 & 0.0787 & 0.0956 & 0.0187 & 0.0546 \\
\hline
\end{tabular}

expectations, ranging from 0 (agreed with none of the seven statements) to seven (agreed with all seven). The Cronbach's alpha for this subscale was 0.73.

\section{Data Analysis}

We conducted logistic regression analyses to estimate associations between heavy episodic drinking and sex-related alcohol expectations and each risky sexual behavior. For each outcome of interest, there were two models: The first model examined the association between heavy episodic drinking and the key outcome, adjusting for social and demographic variables (i.e., age, marital status and education). The second model included sex-related alcohol expectations and heavy episodic drinking as independent variables, adjusting for the same social and demographic variables. All analyses were conducted using STATA 8.0.

\section{RESULTS}

\section{Sample Characteristics}

Among the 312 sexually experienced men in our sample, the mean age was 22.7 years (Table 1 ); the majority ( $80 \%$ ) had never been married. The level of education was fairly high, with $68 \%$ having completed secondary education and $29 \%$ having received some technical or university education. In the past year, $38 \%$ had had two or more sexual partners, 23\% had had sex with a casual partner and $7 \%$ had had sex with a sex worker. In addition, 51\% reported not having used a condom at last sex, and 32\% had not used a condom at last sex with a casual partner. Furthermore, 36\% were heavy episodic drinkers. Fifty-six percent held at least one sex-related belief about alcohol; the beliefs most commonly cited by respondents were "I enjoy having sex more if I have had some alcohol" (56\%), "Women can have orgasms more easily if they have been drinking" (48\%) and "I feel more masculine after a few drinks" (36\%).

\section{Multivariate Analysis}

In the multivariate models that controlled only for age, marital status and education, heavy episodic drinking was associated with an increased risk of having had multiple partners in the past year (odds ratio, 3.1) and having had at least one casual partner in the past year (2.7-Table 2). Heavy episodic drinking was only marginally associated with having had sex with a sex worker in the past year; no association was found between heavy episodic drinking and either of the condom use variables.

When sex-related alcohol expectations were added to the models, the associations between heavy episodic drinking and having had multiple partners and casual partners in the previous year remained significant but were slightly attenuated (odds ratios, 2.8 and 2.5, respectively); the marginal association between heavy drinking and having had sex with a sex worker became nonsignificant. In addition, sex-related alcohol expectations were associated with three of the five risky sexual behaviorsmultiple partners, no condom use at last intercourse and no condom use at last intercourse with a casual partner (1.2-1.3)-but only marginally associated with sex with casual partners and sex workers.

\section{DISCUSSION}

In our community sample of young adult men living in a Peruvian shantytown, heavy episodic drinking was associated with two of the five risky sexual behaviors we examined. In addition, after we controlled for alcohol consumption, sex-related alcohol expectations had an independent effect on three of the five risky sexual behaviors. Therefore, sex-related alcohol expectations may help explain the link between alcohol consumption and risky sexual behaviors only partially accounted for by the pharmacological effects of alcohol.

Before detailed discussion of these results, it is important to note the limitations of the study. First, because of the cross-sectional research design and retrospective data, we could not establish causality. As a result, it is not possible to be certain that alcohol was used just before or while engaging in risky sexual acts. Second, the study sample was a randomly selected group of men from a shantytown in a Latin American country; thus, our results may not be generalizable to other socioeconomic groups or locations. Third, the size of the sample was small, limiting our analytical ability: For example, few participants re- 
ported having sex with a sex worker during the last year, making it impossible to obtain reliable results for this outcome. Fourth, data were self-reported and could be unreliable due to faulty recall or social desirability bias; however, previous research suggests that bias in self-reports of alcohol use and sexual behaviors is low in carefully conducted studies. ${ }^{28,29}$ Fifth, the dependent variable "condom use at last sex" did not distinguish between types of partners. Hence, we also analyzed data on "condom use at last casual sex" to deal with this limitation. And finally, we did not assess such personal variables as general sensation-seeking behavior and mental health. Because these personal variables could result in high risk-taking behaviors independent of alcohol use, they could generate spurious associations with risky sexual behaviors, especially among heavy episodic drinkers.

Notwithstanding these limitations, our findings are of interest because of the strong association found between heavy episodic drinking and two risky sexual behaviorshaving had two or more sexual partners in the past year and having had sex with a casual partner in the past yeareven after adjusting for sex-related alcohol expectations. Therefore, the hypothesis that heavy episodic drinking is independently associated with risky sexual behaviors is confirmed by our study. As a powerful psychoactive drug, alcohol could affect the drinker's ability to evaluate sexual risk. Thus, impaired information processing may contribute to risky sexual behaviors by focusing the drinker's attention on immediate positive consequences and reducing his ability to process potential negative consequences. ${ }^{30}$

We did not find any association between heavy episodic drinking and nonuse of condoms at last sex or nonuse of condoms at last sex with a casual partner. This nonfinding supports previous findings that condom use is not impaired by alcohol., ${ }^{4,-33}$ In fact, contextual and situational factors associated with unprotected sex may differ from factors commonly linked with risky sexual behaviors. For example, nonuse of condoms is associated with the use of other contraceptives or the partners' age. ${ }^{33}$ In addition, condoms may be more likely to be used when sex is planned than when it is not. ${ }^{31}$ An alternative explanation is that at least some heavy episodic drinkers may have learned from prior experiences that they are more likely to engage in sex while under the influence of alcohol, and hence have prepared themselves for such situations (i.e., by having a condom or learning to negotiate condom use). Further research is needed to disentangle the complex relationship between condom use and alcohol use, especially in regions of the world where the prevalence of STIs, including HIV, is increasing.

Furthermore, our results support the hypothesis that sex-related alcohol expectations are independently associated with risky sexual behaviors, such as having multiple partners or not using condoms. Several studies conducted in developed countries have established that people with greater positive expectations of alcohol's effects consume more alcohol. ${ }^{34}$ Additionally, some evidence suggests that expectations are more strongly associated with drinkingrelated consequences than consumption amount, ${ }^{35}$ and that possible consequences can include risky sexual behaviors. ${ }^{12,36}$ And because expectations are modified as drinking experience is accumulated, men in their 20 s could be especially susceptible to the effect of beliefs about the impact of alcohol on sexual behavior: For example, a new drinker may be influenced to have sex with a casual partner by the belief that alcohol enhances sexual performance, whereas an experienced drinker may drink for other reasons (e.g., habit, cultural norms) and be more conscious about alcohol's negative effects. ${ }^{35}$

Overall, our findings indicate that alcohol use is an important factor to consider when designing programs aimed at preventing risky sexual behaviors. The association between sex-related alcohol expectations and risky sexual behaviors, however, suggests that in research related to alcohol or other drug use, it is also important to consider and control for an individual's expectations of these substances' effects. Interventions focusing on changing beliefs about alcohol's effects could reduce both the amount of consumption and such risky sexual behaviors as unprotected sex. This is particularly relevant to interventions targeting men younger than 35, whose expectations of the positive effects of alcohol consumption have proven to be particularly strong. ${ }^{34,37}$ Finally, it is important to teach young people how to deal with advertising messages that portray alcohol and sexuality as complementary, especially in developing countries where regulations for mass media messages are lacking.

\section{REFERENCES}

1. Brook DW et al., The longitudinal relationship between drug use and risky sexual behaviors among Colombian adolescents, Archives of Pediatric and Adolescent Medicine, 2002, 156(11):1101-1107.

2. McEwan RT et al., Sex and the risk of HIV infection: the role of alcohol, British Journal of Addiction, 1992, 87(4):577-584.

3. Cooper ML, Peirce RS and Huselid RF, Substance use and sexual risk taking among black adolescents and white adolescents, Health Psychology, 1994, 13(3):251-262.

4. Staton $\mathrm{M}$ et al., Risky sex behavior and substance use among young adults, Health \& Social Work, 1999, 24(2):147-154.

5. Cooper ML et al., Stress and alcohol use: moderating effects of gender, coping, and alcohol expectancies, Journal of Abnormal Psychology, 1992, 101(1):139-152.

6. Leigh BC, Alcohol consumption and sexual activity as reported with a diary technique, Journal of Abnormal Psychology, 1993, 102(3):490493.

7. George WH and Stoner SA, Understanding acute alcohol effects on sexual behavior, Annual Review of Sex Research, 2000, No. 11, pp. 92124

8. Goldman MS, The alcohol expectancy concept: applications to assessment, prevention, and treatment of alcohol abuse, Applied and Preventive Psychology, 1994, 3(3)131-144.

9. Brown SA et al., Change in alcohol effect and self-efficacy expectancies during addiction treatment, Substance Abuse, 1998, 19(4):155-167.

10. Oei TP, Fergusson S and Lee NK, The differential role of alcohol expectancies and drinking refusal self-efficacy in problem and nonproblem drinkers, Journal of Studies on Alcohol, 1998, 59(6):704-711.

11. O'Hare T, Risky sex and drinking contexts in freshman first of- 
fenders, Addictive Behaviors, 2005, 30(3):585-588.

12. Fromme K, D'Amico EJ and Katz EC, Intoxicated sexual risk taking: an expectancy or cognitive impairment explanation? Journal of Studies on Alcohol, 1999, 60(1):54-63.

13. Dermen KH, Cooper ML and Agocha VB, Sex-related alcohol expectancies as moderators of the relationship between alcohol use and risky sex in adolescents, Journal of Studies on Alcohol, 1998, 59(1):71-77.

14. Weinhardt LS et al., Sex-related alcohol expectancies predict sexual risk behavior among severely and persistently mentally ill adults, Psychology of Addictive Behaviors, 2002, 16(1):64-67.

15. Leigh BC, The relationship of sex-related alcohol expectancies to alcohol consumption and sexual behavior, British Journal of Addiction, 1990, 85(7):919-928.

16. Zavaleta Martinez-Vargas A and Castro de la Mata R, Epidemiología de Drogas en la Población Urbana Peruana 2005, Monografía de Investigación, Lima, Peru: Centro de Información y Educación de Drogas (CEDRO), 2006, No. 24

17. Myers HF et al., Psychosocial predictors of risky sexual behaviors in African American men: implications for prevention, AIDS Education and Prevention, 2003, 15(Suppl. A):66-79.

18. Cáceres V, Comportamiento sexual de riesgo para ETS/SIDA en adolescentes del Departamento de Lambayeque, Folia Dermatológica Peruana, 1998, 9(9):22-28

19. Bamgbose $O$, Teenage prostitution and the future of the female adolescent in Nigeria, International Journal of Offender Therapy and Comparative Criminology, 2002, 46(5):569-585

20. De Sanjose S et al., Social Differences in Sexual Behaviour and Cervical Cancer, Lyon, France: International Agency for Research on Cancer, 1997, pp. 309-317.

21. Berkman DS et al., Effects of stunting, diarrhoeal disease, and parasitic infection during infancy on cognition in late childhood: a followup study, Lancet, 2002, 359(9306):564-571.

22. Saito $\mathrm{M}$ et al., The value of counting BCG scars for interpretation of tuberculin skin tests in a tuberculosis hyperendemic shantytown, Peru, International Journal of Tuberculosis and Lung Disease, 2004, 8(7):842-847.

23. Checkley W et al., Effect of water and sanitation on childhood health in a poor Peruvian peri-urban community, Lancet, 2004 , 363(9403):112-118.

24. Yamamoto J et al., Alcoholism in Peru, American Journal of Psychiatry, 1993, 150(7):1059-1062

25. Jeannin A et al., Validity and reliability in reporting sexual partners and condom use in a Swiss population survey, European Journal of Epidemiology, 1998, 14(2):139-146.

26. Slutske W, Alcohol use disorders among U.S. college students and their non-college-attending peers, Archives of General Psychiatry, 2005, 62(3):321-327.

27. O'Hare T, Drinking and risky sexual behavior in young women and men: a covalidation study, Journal of Alcohol \& Drug Education, 1998, 43(3):66-77

28. Fishbein M and Pequegnat W, Evaluating AIDS prevention interventions using behavioral and biological outcome measures, Sexually Transmitted Diseases, 2000, 27(2):101-110.

29. Siegel K, Krauss BJ and Karus D, Reporting recent sexual practices: gay men's disclosure of HIV risk by questionnaire and interview, Archives of Sexual Behavior, 1994, 23(2):217-230

30. Josephs RA and Steele CM, The two faces of alcohol myopia: attentional mediation of psychological stress, Journal of Abnormal Psychology, 1990, 99(2):115-126.

31. Morrison DM et al., Adolescent drinking and sex: findings from a daily diary study, Perspectives on Sexual and Reproductive Health, 2003, 35(4):162-168.

32. Sly DF et al., The association between substance use, condom use and sexual risk among low-income women, Family Planning
Perspectives, 1997, 29(3):132-136.

33. La Brie J, Schiffman J and Earleywine M, Expectancies specific to condom use mediate the alcohol and sexual risk relationship, Journal of Sex Research, 2002, 39(2):145-152.

34. Leigh BC and Stacy AW, Alcohol expectancies and drinking in different age groups, Addiction, 2004, 99(2):215-227.

35. Blume AW et al., Beliefs about drinking behavior predict drinking consequences, Journal of Psychoactive Drugs, 2003, 35(3):395-399.

36. Maisto SA et al., Effects of alcohol and expectancies on HIV-related risk perception and behavioral skills in heterosexual women, Experimental and Clinical Psychopharmacology, 2004, 12(4):288-297.

37. Wiers RW and Kummeling RH, An experimental test of an alcohol expectancy challenge in mixed gender groups of young heavy drinkers, Addict Behavior, 2004, 29(1):215-220.

\section{RESUMEN}

Contexto: El uso del alcohol se identifica frecuentemente como un factor que contribuye a las conductas sexuales de riesgo; sin embargo, los resultados de las investigaciones son contradictorios. Dada la evidencia conflictiva, los investigadores se han concentrado en otros factores, como las expectativas acerca de los efectos del alcohol, mismas que podrían ayudar a explicar las relaciones entre el uso del alcohol y las conductas sexuales de riesgo.

Métodos: Se utilizó un conjunto de datos transversales de 312 hombres con experiencia sexual en edades de 18 a 30 años, residentes de un barrio pobre de Lima, Perú. En modelos de regresión logística, se identificó las asociaciones entre los episodios de consumo excesivo de alcohol y las expectativas de que el alcohol afectaría la experiencia del sexo, y las conductas sexuales de riesgo.

Resultados: El consumo excesivo de alcohol en poco tiempo se asoció con el hecho de haber tenido dos o más parejas sexuales y con haber tenido relaciones sexuales con una pareja casual en el año anterior (razones de momios de 2.8 y 2.5, respectivamente). Después de controlar la variable de consumo de alcohol, las expectativas de que el alcohol afectaría la experiencia sexual se asociaron con estas conductas sexuales de riesgo, así como con el hecho de no usar condón en la última relación sexual (1.2); y de no usar condón en la última relación sexual con una pareja casual (1.3).

Conclusión: Las creencias acerca del efecto del alcohol en el desempeño sexual podrían ayudar a explicar los vínculos entre el consumo de alcohol y las conductas sexuales de riesgo, los cuales no se explican completamente por los efectos farmacológicos del alcohol.

\section{RÉSUMÉ}

Contexte: La consommation d'alcool est souvent identifiée comme facteur contribuant aux comportements sexuels à risques. Les résultats de la recherche sont cependant mixtes. Face aux données contradictoires, la recherche s'est concentrée sur d'autres facteurs, tels que les attentes relatives aux effets de l'alcool susceptibles d'expliquer le rapport entre sa consommation et la prise de risques sexuels.

Méthodes: Les données transversales relatives à 312 hommes de 18 à 30 ans sexuellement actifs, dans un bidonville de Lima (Pérou), ont servi, par régression logistique, à identifier les 
liens entre une forte consommation épisodique d'alcool et les attentes de nature sexuelle relatives à l'alcool et aux comportements sexuels risqués.

Résultats: La forte consommation épisodique d'alcool s'est révélée associée au fait d'avoir eu au moins deux partenaires sexuelles et d'avoir eu des rapports sexuels avec une partenaire de passage au cours des 12 derniers mois écoulés (rapports de probabilités, 2,8 et 2,5, respectivement). Après contrôle de la consommation d'alcool, les attentes de nature sexuelle relatives à l'alcool apparaissent associées à ces comportements sexuels à risque élevé, ainsi qu'à l'absence de recours au préservatif lors des derniers rapports $(1,2)$ comme lors des derniers rapports avec une partenaire de passage $(1,3)$.

Conclusion: Les croyances quant à l'effet de l'alcool sur les comportements sexuels pourraient aider à éclaircir les liens entre la consommation d'alcool et les comportements à risques que les effets pharmacologiques de l'alcool n'expliquent pas complètement.

\section{Acknowledgments}

The research on which this article was based was supported by grants from the Peruvian-Belgium Cooperation, the National Institute of Drug Abuse (NIDA D43 TW05819) and the National Institutes of Health (NIH R01 DK63041 and NIH T35 AI07646), and by the Ellison Medical Foundation. The authors wish to acknowledge the faculty in the Department of Epidemiology, Michigan State University, for their assistance and guidance in data analysis.

Author contact: galvezbuccollini@yahoo.com 